\title{
Identification of financial and macroeconomic shocks in a VAR model of the Polish economy. A stability analysis ${ }^{1}$
}

\author{
Magdalena Ulrichs ${ }^{2}$
}

\begin{abstract}
Dynamic macroeconomic models (both VAR and DSGE) currently play a very significant role in macroeconomic modelling. But these types of models rarely take into account the impact of financial markets on the behaviour of economies, they are rather more focused on the monetary transmission mechanism. The financial crisis of 2007-2008 highlighted the impact of the financial market on the macroeconomy. In this context macroprudential policy and financial stability analysis has gained a stronger meaning. The main aim of the paper is to estimate a model that simultaneously explains the dynamics of macroeconomic and financial variables and to assess whether the identified relationships are stable over time. Therefore, based on the estimated empirical structural vector autoregression model explaining the interactions between the real economy, the financial system and monetary policy in Poland, financial and macroeconomic shocks were identified. It was shown that the impulse reaction functions changed after the financial crisis. On the basis of Markov-Switching vector autoregression model probabilities of transitions between states of the economy and the regime-dependent impulse reaction functions were estimated.
\end{abstract}

Keywords: VAR models, impulse response functions, Markov-Switching VAR models, structural changes.

JEL codes: C32, C58, E47.

\section{Introduction}

The financial market is strongly connected with the production sector, the international environment and monetary policy. Especially in case of financial crisis, financial sector losses can be transferred to the real economy. Moreover losses caused by the crisis stemming from the financial sector are compounded in the case of an increasing level of financial integration in the economy.

\footnotetext{
${ }^{1}$ Article received 30 July 2017, accepted 22 January 2018.

${ }^{2}$ University of Lodz, Department of Econometrics, Faculty of Economics and Sociology, Rewolucji 1905 r. 41, 90-214 Łódź, Poland, magdalena.ulrichs@uni.lodz.pl.
} 
After the global financial crisis that began with the collapse of Lehman Brothers Holdings Inc. and the failure of subprime loans in 2008 a growing role of research on the transmission of the shocks from the financial sector and the analysis of macroprudential policy tools is observed in the literature (see e.g.: Hollo, Kremer, \& Lo Duca, 2012; Kremer, 2015; Popp \& Zhang, 2016; Tamási \& Világi, 2011).

Although Poland is an example of an economy in which many negative consequences of the financial crisis were not observed it is still interesting to analyse the stability of the relationships between financial and real variables after the end of the global financial crisis.

The main objective of the article is to estimate a model that simultaneously explains the dynamics of macroeconomic and financial variables and to assess whether the identified relationships are stable over time and if there is confirmation of the unstable behaviour of these relationships to assess if the global financial crisis had changed these relationships. Analysis of the links between the monetary policy, the financial and banking sector and the real economy is made within a vector autoregression model (VAR) framework.

Empirical analysis is based on Polish quarterly data for the period 19982016. Fundamental shocks are estimated on the basis of a VAR model. Regimedependent impulse response functions show how the reactions of the endogenous variables in the model to fundamental disturbances differ across the regimes identified.

The paper contributes to the main strands of literature. The first one estimates the macroeconomic effects of monetary policy, the second is focussed on the influence of financial instability on the macroeconomy. In the presented model the influence of both monetary and financial shocks was estimated. For this purpose the model that simultaneously explains the dynamics of macroeconomic and financial variables was estimated. Furthermore as an empirical example Polish data was used as this is an interesting example of an economy which did not suffer much after the global financial crisis. In the model the stability of bank sector was approximated by the ratio of non-performing loans to the total loans in the monetary financial institutions (the common practice is to use total loans or different loan subcategories - e.g. Hartmann, Hubrich, Kremer, \& Tetlow, 2014; Kanngiesser, Martin, Maurin, \& Moccero, 2017; Kremer, 2015). Moreover a broad stability analysis of the relationships was conducted and the results were confirmed by the estimations of Markov-Switching VAR models.

The structure of the article is as follows. Section 1 introduces the relationships between the financial and macroeconomic sectors in the Polish economy. Section 2 presents the results of shock identification in a vector autoregression model. Section 3 is devoted to a recursive analysis of the impulse response functions, based on Markov-Switching VAR models it contains estimate regimedependent impulse response functions. The paper is closed with conclusions. 


\section{Macro-financial relationships in the Polish economy}

The empirical model is focused on the estimation of linkages between the monetary policy, the financial and banking sector and the real economy. The resilience of the economy to macro-financial shocks and the stability of financial system are the main fetaures of appropriate transmission of funds between savers and borrowers. Financial system stability is a situation when the system performs its functions in a continuous and efficient way, even when unexpected disturbances occur on a significant scale. The stability of the financial system is a necessary condition for ensuring sustainable economic growth in the long term. As maintaining price stability is the main task of central bank in Poland and the financial system plays a key role in the transmission of monetary impulses to the real economy, financial system instability may disturb the efficiency of the bank's policy. The role of the financial channel is widely emphasized in the literature e.g. by (Boivin, Giannoni, \& Stevanovic, 2013; Nason \& Tallman, 2015; Popp \& Zhang, 2016). In accordance with the main purpose of the article the channels of transmission of monetary and financial shocks to the economy are considered.

In the case of Poland the stability of the banking system, which accounts for two thirds of the assets of the Polish financial system ${ }^{3}$, is of particular importance for the financial system stability. Therefore special emphasis is put on the analysis and assessment of banking system stability (Kanngiesser et al., 2017). Banks provide various services to the agents of financial and real sectors channelling financial funds between savers and borrowers. As banks play a crucial role in financing the economy the occurrence of disturbances in banking system can lead to much distortion in whole sectors of the Polish economy. Therefore maintaining the stability of the banking sector is the key prerequisite for financial stability in Poland (Osiński, 2016). The monetary and financial shocks can be transmitted to the real economy mainly through the bank lending channel (Nilsen, 1999). As (Kishan \& Opiela, 2000) underline in the credit channel banks play a pivotal role in transmission of policy, offering an interesting explanation for the strength, timing and distributional effects of policy shocks.

Further, in the empirical model, the stability of the banking sector in Poland is measured as the share of non-performing loans to the total loans in the monetary financial sector. A rise in this indicator means the reduction of the level of stability of the banking sector and therefore the rise of the risk connected with its destabilization (Wdowiński, 2014) - referred to hereafter as - credit risk.

Since corporate institutions outside the banking system, can raise capital also on a capital market attention is as well paid to the analysis and assessment

\footnotetext{
${ }^{3}$ In 2015 total loans amounted to almost $60 \%$ of gross domestic product and the total assets of monetary financial institutions exceeded $100 \%$ of GDP, while the stock exchange capitalization did not exceed $30 \%$ of GDP.
} 
of capital market stability. The capital market is approximated in the model by changes in the level of Warsaw Stock Exchange Index.

The Polish economy is strongly dependent on external market distortions. In the model the real effective exchange rate as the approximation of foreign disturbances is used.

As a measure of economic activity the real sold production of industry is used instead of the gross domestic product (GDP) which is normally used. The shape of reactions of sold industry production is the same as GDP but the reactions in the case of industry production are stronger. ${ }^{4}$

The analysis of the relationships between financial development and the real economy is based on a vector autoregression model (VAR). This type of model is extensively used in the literature in the analysis of the monetary transmission mechanism (e.g. Arratibel \& Michaelis, 2014; Kapuściński et al., 2016; Polito \& Wickens, 2012; Sack, 2000; Serwa \& Wdowiński, 2016; Górajski \& Ulrichs, 2016), it can also serve as an appropriate tool for measuring the strength and effectiveness of the channels of transmission of financial and monetary shocks.

We estimate a vector autoregression model (VAR) defined as in equation (1) (Lütkepohl, 2005):

$$
y_{t}=A_{0}+A_{1} y_{t-1}+\ldots+A_{P} y_{t-P}+\varepsilon_{t}
$$

where:

$\boldsymbol{y}_{\boldsymbol{t}}$ - vector of endogenous variables,

$\boldsymbol{A}_{P}$ - matrix of autoregression parameters, $p=1, \ldots, P$,

$\boldsymbol{A}_{0}$ - vector of constant term,

$\boldsymbol{\varepsilon}_{t} \sim N I D(0, \boldsymbol{\Sigma})$ - vector of error terms.

The model's parameters were estimated on the Polish quarterly data for period 1998-2016. The model includes the standard monetary policy instrument - interest rates, the measure of economic activity - sold production of industry, real effective exchange rate and is extended to include a banking variable (non-performing loans to total loans in the monetary financial institutions ) and capital markt measure (WIG). The vector of endogenous variables includes the following stationary transformations of (see: results in Table 1) time series:

- WIBOR - nominal interest rate - WIBOR1M (p.p),

- WIG - Warsaw Stock Exchange Index (\%),

- REER - real effective exchange rate (\%),

- NPL - non-performing loans to total loans in the monetary financial institutions (p.p),

- SIP - real sold production of industry (\%).

\footnotetext{
${ }^{4}$ Estimations including gross domestic product instead of sold production of industry are available upon request.
} 
Table 1. $p$-value of ADF and PP test. Null Hypothesis: Variable has a unit root

\begin{tabular}{|c|c|c|}
\hline Variable & $\boldsymbol{p}$-value ADF test & $\boldsymbol{p}$-value PP test \\
\hline WIBOR & 0.0000 & 0.0007 \\
\hline WIG & 0.0001 & 0.0022 \\
\hline REER & 0.0000 & 0.0002 \\
\hline NPL & 0.0275 & 0.0285 \\
\hline SIP & 0.0664 & 0.0091 \\
\hline
\end{tabular}

Source: own computations.

\section{Identification of financial and macroeconomic shocks in a VAR model}

The impact of shocks in the model is based on a recursive identification scheme (Cholesky decomposition). The structuralization of shocks was based on the following identification restrictions (see: equation 2). As financial intermediaries are the main transmitters of monetary policy impulses to the real economy it is assumed that the financial market responds simultaneously to the monetary policy shock and then transmits the impulses to the real economy. These shocks are immediately transmitted to the real economy. These assumptions lead to the following Cholesky structuralization of shocks:

$$
\left[\begin{array}{l}
\xi^{W I B O R} \\
\xi^{W I G} \\
\xi^{R E E R} \\
\xi^{N P L} \\
\xi^{S I P}
\end{array}\right]=\left[\begin{array}{ccccc}
\alpha_{11} & 0 & 0 & 0 & 0 \\
\alpha_{21} & \alpha_{22} & 0 & 0 & 0 \\
\alpha_{31} & \alpha_{32} & \alpha_{33} & 0 & 0 \\
\alpha_{41} & \alpha_{42} & \alpha_{43} & \alpha_{44} & 0 \\
\alpha_{51} & \alpha_{52} & \alpha_{53} & \alpha_{54} & \alpha_{55}
\end{array}\right]\left[\begin{array}{l}
\varepsilon^{W I B O R} \\
\varepsilon^{W I G} \\
\varepsilon^{R E E R} \\
\varepsilon^{N P L} \\
\varepsilon^{S I P}
\end{array}\right],
$$

where: $\xi^{j}$ is the impulse from the equation describing the $j$ variable, and $\varepsilon^{j}$ is the fundamental shock from $j$ variable.

The fundamental macroeconomic shocks in the model: $\varepsilon_{t}^{\text {WIBOR }}, \varepsilon_{t}^{\text {WIG }}, \varepsilon_{t}^{R E E R}$, $\varepsilon_{t}^{N P L}, \varepsilon_{t}^{S I P}$, can be interpreted as the shocks of monetary policy, capital market, exchange rate, credit risk and production, respectively.

Based on the estimated VAR model described in equation (1) and Cholesky ordering as in equation (2), impulse responses of endogenous variables to the structural schocks are generated. In Figure 1 the impulse responses functions of all endogenous variables to the one standard deviation macroeconomic shocks (solid lines ) with 2 standard error bands (dotted line) are reported. 

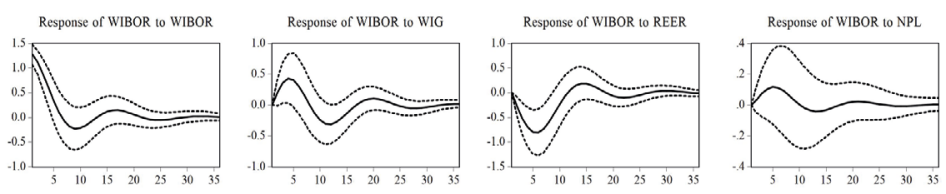

Response of WIBOR to SIP
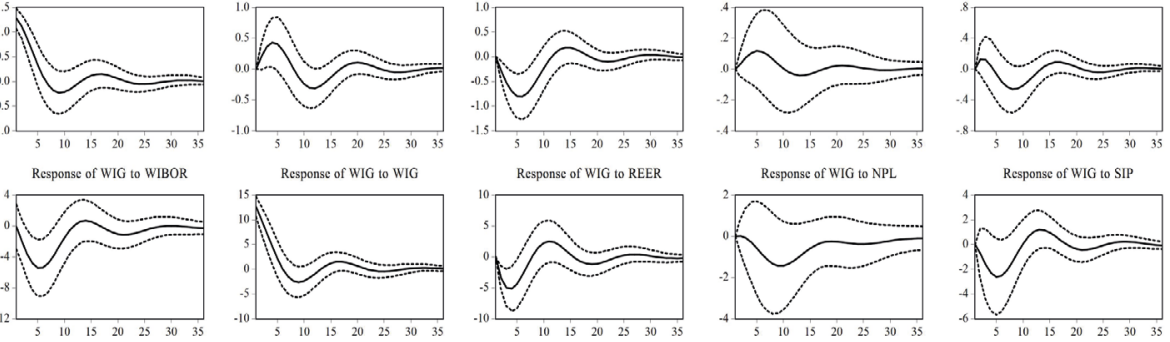

Response of REER to WIG
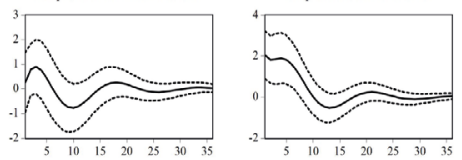

Response of REER to REER

Response of REER to NPL
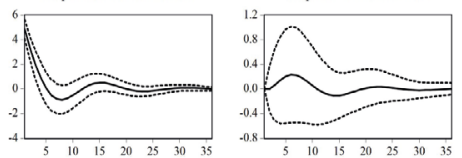

Response of NPL to REER
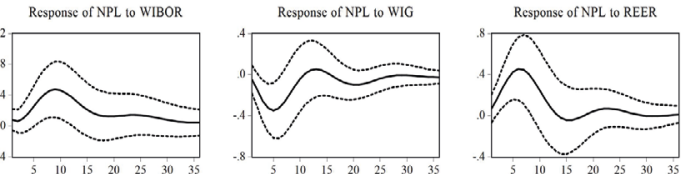

Responsc of NPL to NPL

Response of SIP to WIBOR
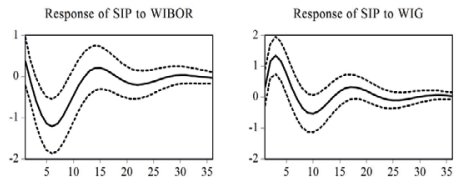

Response of SIP 10 REER
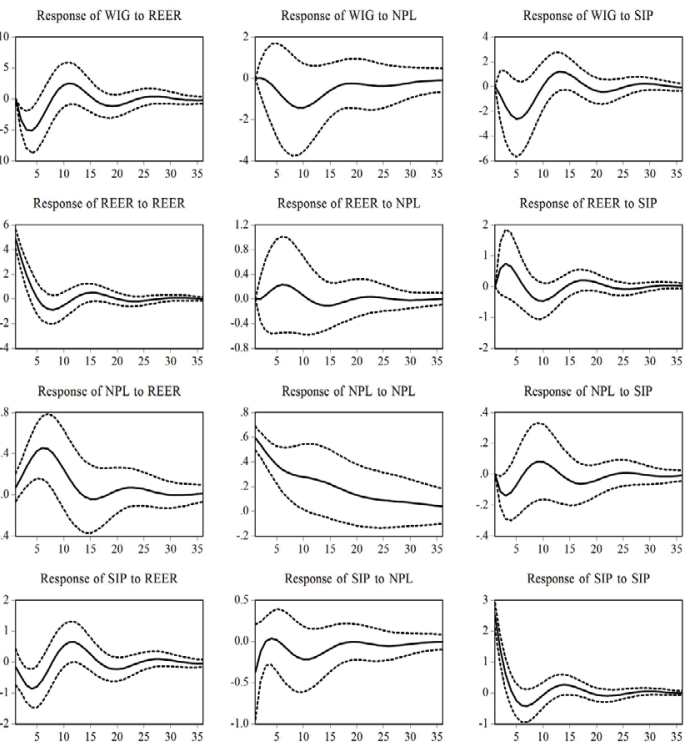

Response of REER to SIP

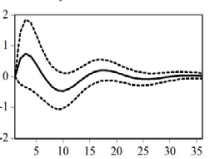

Response of NPL to SIP

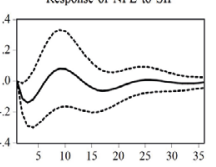

Response of SIP to NPL

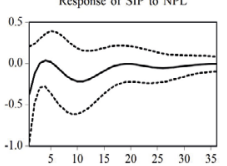

Response of SIP to SIP

Figure 1. Impulse response functions to one standard deviation fundamental shocks (solid lines) with \pm 2 S.E. bands (dotted lines)

Source: own computations.

In the model the negative shock of monetary policy leads to a significant decline in production. A contractionary interest rate shock due to a rise of credit cost and the weakening of economic activity leads to the significant rise in the ratio of non-performing loans to total loans in the monetary financial institutions and capital market development. There is no significant reaction of exchange rates to the monetary policy shock.

A positive capital market shock has significant and advantageous impact both on the banking sector and the real economy. Immediately after a capital market shock about a $2 \%$ appreciation of Polish currency value is observed and a rise of real production is visible. Due to the improvement of the aggregate demand a decline in the non-performing loans in relation to total loans is observed, subsequently inflationary pressure rises which leads to the necessity of raising interest rates.

An exchange rate appreciation shock has a temporary negative effect on production through a slowdown in exports. However, later a positive impact of appreciation on the real sector due to the simultaneous decline in a shortterm interest rate is faced (Kapuściński et al., 2016). The decline of production 
leads to the rise of the share of non-performing loans to total loans that can strengthen significantly a risk of bank sector instability.

A credit risk shock in the model is understood as an increase in the share of non-performing loans to total loans in the monetary financial institutions. A worsening of the repayments of bank loans can lead to a significant rise in the share of non-performing loans to total loans that can have an adverse effect on the stability of banking sector. In the model it can be observed that although banking system reacts significantly to all macroeconomic shocks it does not generate disturbances on the stock exchange. There is also no significant reaction on monetary policy and exchange rates. A significant decline is only observed in the production sector (due to the weakening situation of borrowers and the more difficult conditions for obtaining a bank loan). The results presented confirm the high stability of the banking sector in Poland. The banking sector absorbs shocks from other endogenous variables of the model, but reactions of all variables on the credit risk shock are not statistically significant. This may be due to the relatively good situation of banking sector in Poland during the period analysed. Bank lending grew at a rate that does not generate macroeconomic imbalances. The growth rate of loans to the non-financial sector remained close to the nominal GDP growth. No signs of excessive easing of their lending policy by banks were identified. Changes in banks' lending policies were partly dictated by an adaptation to the environment of low interest rates, as well as increased fiscal burdens and were aimed at increasing the sales of loans with high spreads. The quality of loans to the non-financial sector and the ratio of loan losses to the value of the portfolio gradually improved (Osiński, 2016).

The model reactions of monetary and financial variables to the positive production shock are not statistically significant.

By altering the order of the variables in the system the robustness for the shock identification scheme was checked. If we assume that the production sector do not respond contemporaneously to the financial and monetary variables - but it reacts at least with one quarter lag - the overall conclusions do not change. The magnitiude and the shape of impulse reaction functions are similar, both for use as an activity measure for sold industry production and the gross domestic product.

\section{Stability analysis}

\subsection{Recursive impulse response functions}

In order to asses the stability of the relationships investigated a recursive estimation of impulse response functions was conducted.

The recursive estimators are based on a expanding subsample. The experiment implies that the estimation sample ends in the last quarter of $2005(T=0)$ 
and then the estimation window will widen quarterly until the end of the full sample (4q2016). Each time the impulse response functions are estimated based on the quarterly sample $(T+i)$. It results in 44 recursively updated estimations. All results are presented in Figure 2.

The analysis of recursive estimates leads to interesting conclusions. It can be observed that the shape and level of impulse response functions depend on the estimation sample. The light-coloured lines in Figure 2 group impulse response functions estimated on the sample till the end of the year 2008. From this it is possible to find outlier level of responses for the estimations covering the year 2009 and lastly - the dark-colour lines show the estimation results for period after the year 2009 till 2016. Therefore it can be supposed that the outlier levels result from the financial crisis 2007-2008. The reactions before the crisis differ from the reactions after the global financial crisis erupted.

In order to confirm these results the Markov-Switching vector autoregressive model was estimated. Based on the MS-VAR model it was investigated whether

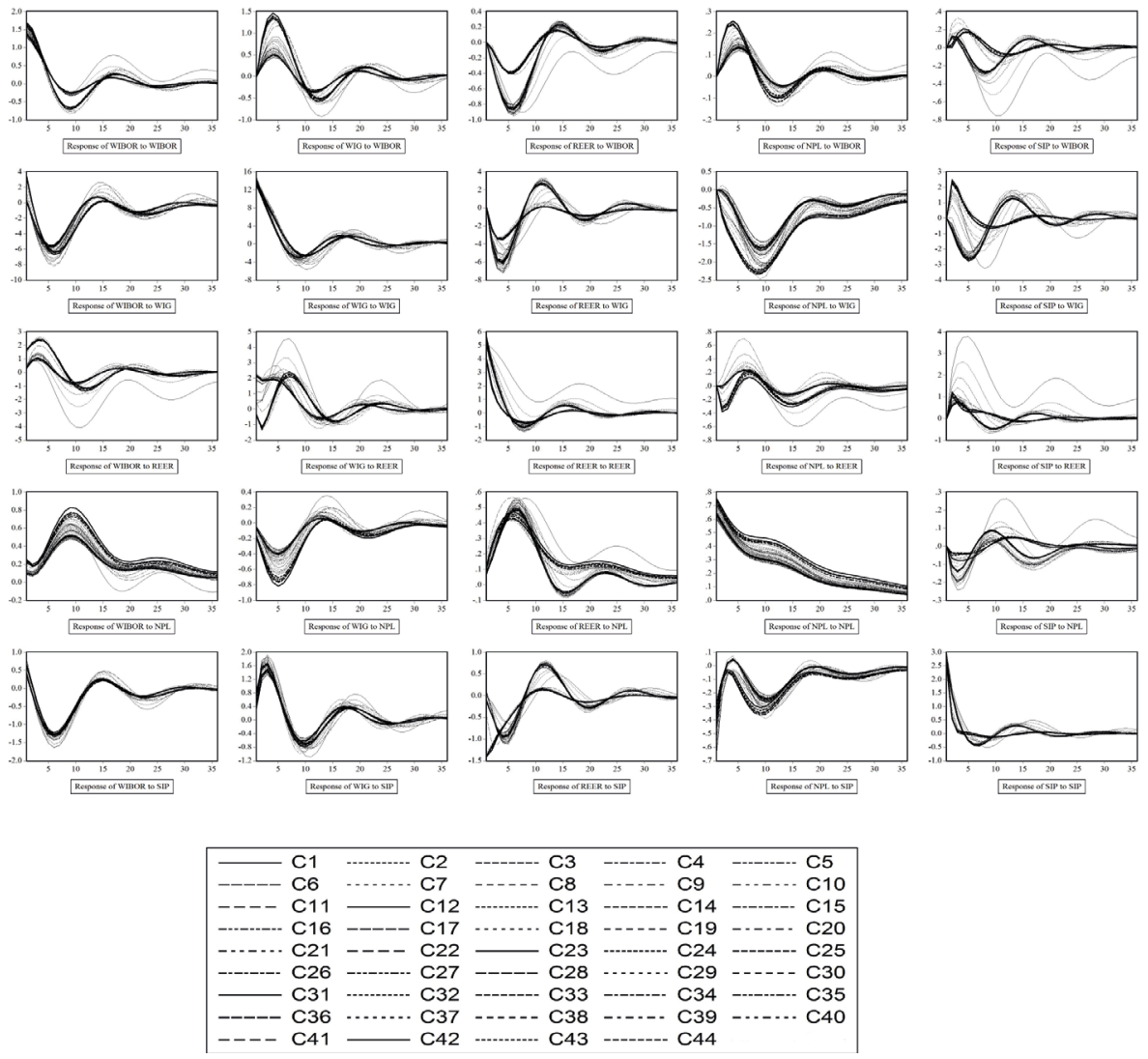

Figure 2. Recursively estimated impulse response functions Source: own computations. 
it is possible to empirically identify different regimes (states) for which the reactions of endogenous variables on fundamental shocks are different.

\subsection{Markov-Switching VAR Model}

Markov-Switching models are the solution to estimation models with changes in the parameters when the moment of change is a priori not known. In macroeconomic analysis linear VAR approximations are often sufficiently accurate but it has to be to remembered that the linearity of relationships imposes several restrictions, including that the responses to structural shocks are invariant as to when the structural shock occurs and to the state of economy at the time when the structural shock occurs. This assumption is usually unrealistic invalidating the use of classical linear models. For example, in case of an economy functioning in different regimes (states), the necessity of using regime-dependent models is obvious (Kilian \& Lütkepohl, 2017). This has led to development of the Markov-Switching vector autoregressive models (MSVAR) in business cycle analysis (see e.g.: Hamilton, 1988, 1990, 1994a, 1994b, 2008).

Hamilton in his analysis of the business cycle used the expectation maximization algorithm (EM) to the estimation of Markov-Switching models. (Krolzig, 1997) has developed univariate Markov-Switching analysis to the multivariate case and discussed the EM algorithm for different special cases of data generating processes. Shock identification in the case of regime switching was not widely used in time-series literature (e.g. Ehrmann, Ellison, \& Valla, 2003; Krolzig, 2006; Lanne \& Lütkepohl, 2008).

The idea of Markov-Switching models takes into account the fact that the data generating process depends on an unobservable variable representing the state of the economy. This variable represents the probability that the system is in the particular state (regime), and the model parameters depend on the variable representing the state of the economy $S_{t} \in\{1, \ldots, k\}$ in period $t$. The stochastic process generating unobservable states is the ergodic Markov chain that determines the probability of moving from state $j$ to state $i$. If the number of states is finite, $(i=1, \ldots, k)$ the probability that system is in period $t$ in state $i$ on condition that in period $t-1$ was in state $j$ is given by $p_{i j}=P\left(S_{t}=j \mid S_{t-1}=i\right)$, where $\sum_{j=1}^{k}=p_{i j}=1 \wedge i \in\{1, \ldots, k\}$.

Markov-Switching VAR model (MS-VAR) is given by equation (3):

$$
\boldsymbol{y}_{t}=\boldsymbol{A}_{0, S_{t}}+\boldsymbol{A}_{1, S_{t}} \boldsymbol{y}_{t-1}+\ldots+\boldsymbol{A}_{P, S_{t}} \boldsymbol{y}_{t-P}+\boldsymbol{\varepsilon}_{t}
$$

where:

$y_{t} \quad$ - vector of endogenous variables,

$A_{p, s_{t}}$ - matrix of autoregressive parameters dependent on the state of a Markov chain $S_{t}, p=1, \ldots, P$, 
$\boldsymbol{\varepsilon}_{t} \mid S_{t} \sim N I D\left(0, \Sigma\left(S_{t}\right)\right)$ - is white noise with the covariance matrix $\boldsymbol{\Sigma}\left(S_{t}\right)$ depended on the state of a Markov chain $S_{t}$.

The maximum likelihood estimator of MS-VAR models may be unreliable in small samples and may be impractical for large models (Droumaguet, 2012; Kilian \& Lütkepohl, 2017). Moreover it is unrealistic to suppose that the moment of regime change is the same for all relationships in the model. Therefore, in order to limit the number of parameters for estimation, the restriction on the matrix $\boldsymbol{A}_{1, S_{t}}$ of autoregression parameters was introduced into the MS-VAR(1) model. The restrictions imposed are based on the recursive analysis of impulse response functions. ${ }^{5}$

For the MS-VAR(1) model:

$$
\boldsymbol{y}_{t}=\boldsymbol{A}_{0}+\boldsymbol{A}_{1, S_{t}} \boldsymbol{y}_{t-1}+\boldsymbol{\varepsilon}_{t}
$$

the matrix $A$ was as follows (5):

$$
A_{1, S_{t}}=\left[\begin{array}{lllll}
a_{11} & a_{12} & a_{13, S} & a_{14} & a_{15, S} \\
a_{21} & a_{22} & a_{23} & a_{24} & a_{25, S} \\
a_{31} & a_{32, S} & a_{33} & a_{34} & a_{35} \\
a_{41} & a_{42} & a_{43} & a_{44} & a_{45, S} \\
a_{51} & a_{52} & a_{53, S} & a_{54} & a_{55}
\end{array}\right],
$$

where $\boldsymbol{\varepsilon}_{t} \mid S_{t} \sim \operatorname{NID}\left(0, \boldsymbol{\Sigma}\left(S_{t}\right)\right)$.

The MS-VAR(1) model with $k=3$ states was estimated.

During the period analysed 3 states (regimes) of the economy were identified. Figure 3 presents the smoothed transition probabilities of the system in each of the regimes. The first state is a state of the smallest variance while during state 3 the variability is the highest. State 1 corresponds to the period 2005-2008 and 2010-2016. From the beginning of 1999 till the end of 2003 the economy was under the second state. The periods related to the high variability and unpredictably of the reactions are recognised as the third state. The third state is the transitory state - it covers the periods of changes between regimes. The moments of changes between regimes are related to important events in the Polish economy. These are: introducing an inflation targeting policy in Poland (1998), joining the European Union (2004) and the global financial crisis (2008-2009).

For each regime, as in (Ehrmann et al., 2003), regime-dependent impulse response functions were estimated under the assumption that within each regime, responses are derived exactly as if the system was a VAR model with $\boldsymbol{A}_{1, s_{t}}$

${ }^{5}$ Results for the MS-VAR model without restrictions on the parameters do not confirm the existence of structural changes in the system. 


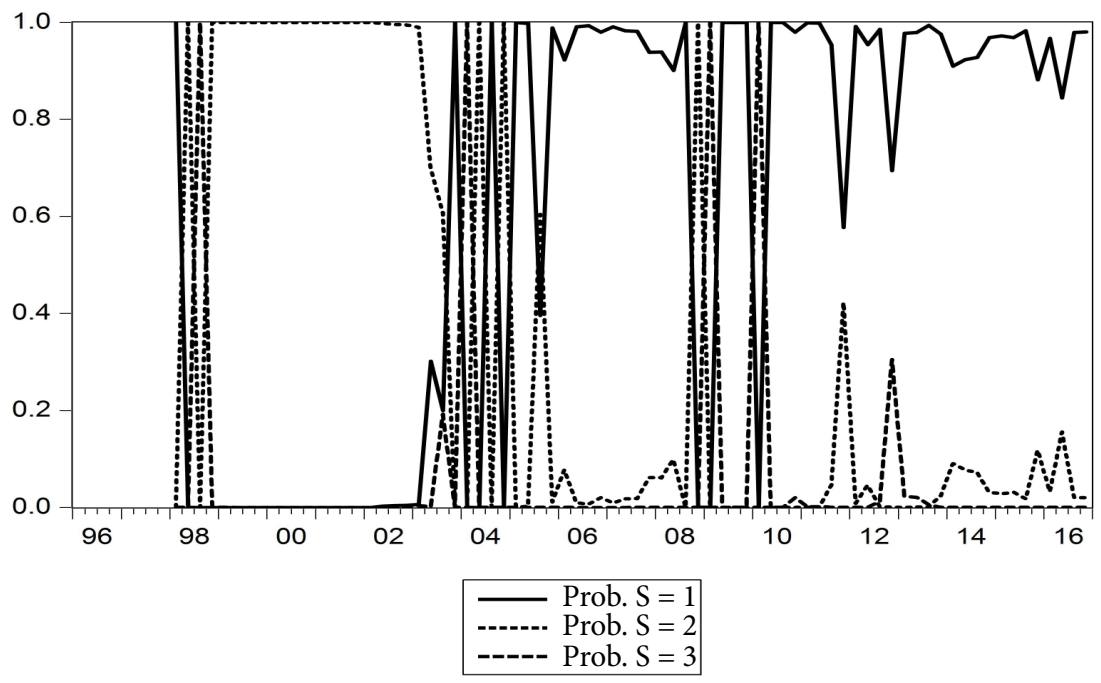

Figure 3. State probabilities

Source: own computations.

matrix of autoregressive parameters and the structural identification does not depend on the regime.

The general model contains regime-dependent impulse response functions, defined as in equation (6), corresponding to the reactions of endogenous variables to the disturbances in $k$ regimes. Expected changes in the endogenous variables at time $t+h$ to a one standard deviation fundamental shock at time $t$ are conditional on the regime $i$, (Ehrmann, Ellison, \& Valla, 2001).

$$
\left.\frac{\delta E_{t} Y_{t+h}}{\delta \varepsilon_{k, t}}\right|_{S_{t}=\ldots=S_{t+h}=i}=\Theta_{k i, h},
$$

for $h \geq 0$.

The shapes of regime-dependent response functions for one standard deviation shocks for the first and second state of the economy are presented in Figure 4.

The regime-dependent impulse response functions confirm the earlier recursive analysis of responses. The magnitude of impulse response functions depends on the state of economy. The impulse response functions for third state indicate that the reactions of an economy to shocks are unstable. All impulse response functions in the third state are exploding.

The magnitude of reactions during the second state are in most cases deeper than during the first regime. In case of the reaction of REER to monetary policy shock, reaction of WIBOR to a capital market shock and to a credit risk shock 

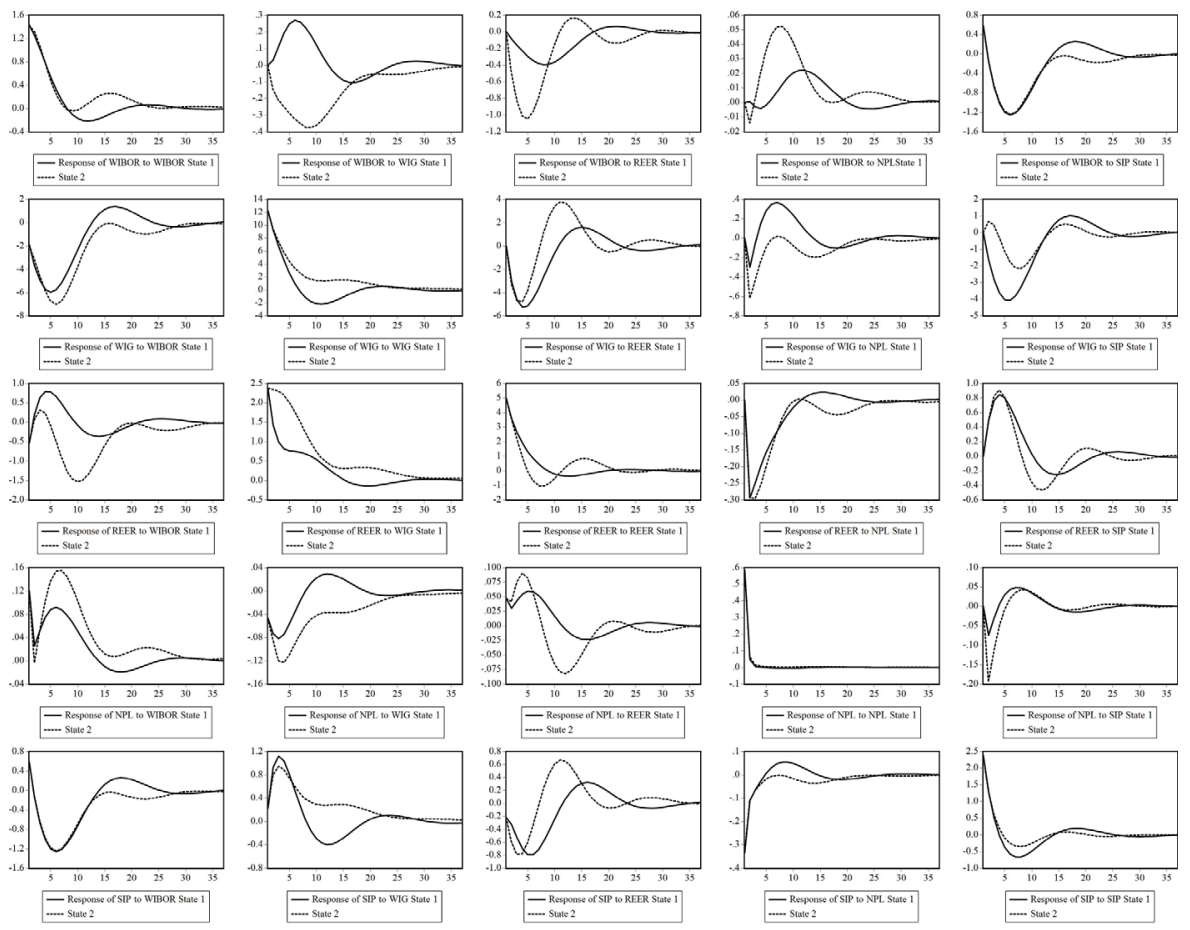

Figure 4. Regime-dependent impulse response functions for the first and the second state of economy

Source: own computations.

there is a change of sign of regime-dependent impulse response functions. During higher variance regime monetary policy reacts much more strongly to the credit risk shock than during a period of smaller variability when the reaction is not significant.

\section{Conclusions}

This paper presents the conclusions from the estimates of VAR and the Markov-Switching VAR model for the Polish economy. The estimated models are used to asses the links between monetary, financial and real variables and to asses the stability of the estimated relationships. Based on MS-VAR models it was possible to estimate the probabilities of being in particular regime.

The empirical results suggest that financial shocks influence significantly the real economy and the banking sector. A positive interest rate shock influences the stock exchange negatively, causes an appreciation of the Polish currency, increases the ratio of non-performing loans to the total loans and has a nega- 
tive influence on production. A positive capital market shock has a beneficial influence - it causes an appreciation of the Polish currency and has a positive effect on the credit market and the production sector. The appreciation of the Polish currency has a negative impact on interest rates, the stock exchange, the production sector and the stability of the banking sector. Shocks derived from the financial system (capital market, exchange rate) are transmitted to the real sector of the economy. The shock of non-performed loans has no significant effect on other endogenous variables of the system. The shock of monetary policy has a significant impact on both the financial market, the banking sector and the real economy.

Based on the Markov-Switching models with hidden chains three states of the economy were identified, varying in volatility and the magnitude of shocks. The first state can be identified as a state of less variability, the second state is the state of greater variance, the third state - the transition state - is the state with the highest variability. The third regime is characterized by a loss of system stability. Impulse response functions of endogenous variables to shocks are conditional on the state in which the system is located.

\section{References}

Arratibel, O., \& Michaelis, H. (2014). The impact of monetary policy and exchange rate shocks in Poland: Evidence from a time-varying VAR. European Central Bank, Working Paper Series: 1636(16). Retrieved from https://www.ecb.europa.eu/pub/ pdf/scpwps/ecbwp1636.pdf?fc18ea39c8725b6cfb4ac7f3064f92b5

Boivin, J., Giannoni, M. P., \& Stevanovic, D. (2013). Dynamic effects of credit shocks in a data-rich environment. Staff Report, Federal Reserve Bank of New York, 615.

Droumaguet, M. (2012). Markov-Switching vector autoregressive models: Monte Carlo experiment, impulse response analysis, and Granger-Causal analysis. Phd. Thesis. https://doi.org/10.2870/63610

Ehrmann, M., Ellison, M., \& Valla, N. (2001). Regime-dependent impulse response functions in a Markov-Switching vector autoregression model. Economics Letters, 78(3), 295-299. https://doi.org/10.1016/S0165-1765(02)00256-2

Ehrmann, M., Ellison, M., \& Valla, N. (2003). Regime-dependent impulse response functions in a Markov-Switching vector autoregression model. Economics Letters, 78, 295-299.

Górajski, M., \& Ulrichs, M. (2016). Optymalne wrażliwe na ryzyko strategie polityki pieniężnej dla Polski (Optimal risk-sensitive monetary policy for the Polish economy). Bank i Kredyt, 47, 1-32.

Hamilton, J. D. (1988). Rational-expectations econometric analysis of changes in regime. An investigation of the term structure of interest rates. Journal of Economic Dynamics and Control, 12(2-3), 385-423. https://doi.org/10.1016/0165-1889(88)90047-4

Hamilton, J. D. (1990). Analysis of time series subject to changes in regime. Journal of Econometrics, 45, 39-70. 
Hamilton, J. D. (1994a). Autoregressive conditional heteroskedacity and changes in regime. Journal of Econometrics, 64, 307-333. https://doi.org/10.1016/03044076(94)90067-1

Hamilton, J. D. (1994b). Time Series Analysis. Princeton: Princeton University Press.

Hamilton, J. D. (2008). Regime-Switching Models. Prepared for: The New Palgrave Dictionary of Economics.

Hartmann, P., Hubrich, K., Kremer, M., \& Tetlow, R. J. (2014). Melting Down: Systemic Financial Instability and the Macroeconomy. European Central Bank (ECB), $1-42$.

Hollo, D., Kremer, M., \& Lo Duca, M. (2012). CISS - A composite indicator of systemic stress in the financial system. European Central Bank (1426). Retrieved from http://papers.ssrn.com/abstract=2018792

Kanngiesser, D., Martin, R., Maurin, L., \& Moccero, D. (2017). Working Paper Series Estimating the impact of shocks to bank capital in the euro area. ECB Working Paper Series (2077).

Kapuściński, M., Kocięcki, A., Kowalczyk, H., Łyziak, T., Przystupa, J., Stanisławska, E., ... Wróbel, E. (2016). Monetary policy transmission mechanism in Poland. What do we know in 2015? National Bank of Poland Working Papers (249).

Kilian, L., \& Lütkepohl, H. (2017). Structural vector autoregressive analysis. (Themes in Modern Econometrics). Cambridge: Cambridge University Press. doi: $10.1017 / 9781108164818$

Kishan, R. P., \& Opiela, T. P. (2000). Bank size, bank capital, and the bank lending channel. Journal of Money, Credit and Banking, 32(1), 121-141. https://doi. org/10.2307/2601095

Kremer, M. (2015). Macroeconomic effects of financial stress and the role of monetary policy: a VAR analysis for the euro area. International Economics and Economic Policy, 13(1), 105-138. https://doi.org/10.1007/s10368-015-0325-z

Krolzig, H.-M. (1997). Markov-Switching vector autoregressions. Modelling, statistical interference, and application to business cycle analysis. Lecture Notes in Economics and Mathematical System, 454.

Krolzig, H.-M. (2006). Impulse-response analysis in Markov-Switching vector autoregressive models. Working Paper, 1(2), 1-17.

Lanne, M., \& Lütkepohl, H. (2008). Identifying monetary policy shocks via changes in volatility. Journal of Money, Credit and Banking, 40(6), 1131-1149. https://doi. org/10.1111/j.1538-4616.2008.00151.x

Lütkepohl, H. (2005). New introduction to multiple time series analysis. Springer Science \& Business Media.

Nason, J. M., \& Tallman, E. W. (2015). Business cycles and financial crises: the roles of credit supply and demand shocks. Macroeconomic Dynamics, 19(4), 836-882.

Nilsen, J. H. (1999). Trade credit and the bank lending channel. Working Paper, Study Center Gerzensee, 99(4), 1-48.

Osiński, J. (2016). Financial Stability Report. NBP, Financial Stability Report, (December), 1-32. https://doi.org/10.2854/206439

Polito, V., \& Wickens, M. (2012). Optimal monetary policy using an unrestricted VAR. Journal of Applied Econometrics, 27, 525-553. 
Popp, A., \& Zhang, F. (2016). The macroeconomic effects of uncertainty shocks: the role of the financial channel. Journal of Economic Dynamics and Control, 69, 319-349. https://doi.org/10.1016/j.jedc.2016.05.021

Sack, B. (2000). Does the fed act gradually? A VAR analysis. Journal of Monetary Economics, 46, 229-256. https://doi.org/10.1016/S0304-3932(00)00019-2

Serwa, D., \& Wdowiński, P. (2016). Macro-financial linkages in the Polish economy: combined impulse-response functions in SVAR models. National Bank of Poland Working Papers, (246), 1-46.

Tamási, B., \& Világi, B. (2011). Identification of credit supply shocks in a Bayesian SVAR model of the Hungarian Economy. MNB Working Papers, 7, 1-21. Retrieved from http://www3.mnb.hu/letoltes/wp-2011-07.pdf

Wdowiński, P. (2014). Makroekonomiczne czynniki ryzyka kredytowego w sektorze bankowym w Polsce (Macroeconomic credit risk factors in Poland's banking sector). Gospodarka Narodowa, 4(272), 55-77. 